\title{
Numbers and Letters: Exploring an Autistic Savant's Unpractised Ability
}

\author{
Linda Pring and Beate Hermelin \\ Psychology Department, Goldsmiths College, University of London, London SE14 6NW, UK
}

\begin{abstract}
This paper describes an individual with autism and high-level calendar calculation ability who could perform a set of unpractised letter/number association tasks. The savant's performance was compared with that of two control participants, one a departmental secretary and the other a professor of mathematics. The facility with which the savant could master the rules governing the relationships between the series of items suggests that he possessed a flexibility of mental processing transcending his ability of calendar calculation. Furthermore, he could recalibrate previous knowledge to solve new hitherto unpractised tasks. When presented with novel problems, the savant, unlike the mathematician, made no initial errors at all on any of the presented tasks, thereby indicating his fast and spontaneous recognition of new rules and of new relationships between items. It is concluded that a cognitive style of 'weak central coherence' as adopted by autistic savants may protect single representations from being retained in the form of stable enduring wholes, and that such a segmentation strategy may allow for the transformation, reorganization and reconstruction of the relationship between single items of information.
\end{abstract}

\section{Introduction}

Talent and practise are both essential features for obtaining excellence in a specific domain while neither of these seems to depend on high intelligence. This is indeed demonstrated by the phenomenon of 'idiots savants', who are individuals with both mental handicaps and special gifts. Their achievements do not perhaps extend to the highest levels, but nevertheless exceed those to which most of us aspire or obtain in fields such as music, art and numerical ability. The term 'idiot savant' was first used by Binet in 1894 to describe the concurrence in individuals of impaired general cognitive functioning together with an above average specific ability. Such people appear to be able to use processing strategies within a particular domain that seem independent of their general level of cognitive functioning (e.g. O'Connor and Hermelin, 1989; Pring and Hermelin, 1993). It is of considerable interest that most savants have a diagnosis of autism or Asperger's syndrome, although such individuals form only a small part of those with general mental handicap impairment. Are there perhaps some characteristics of the cognitive style adopted by those with autism that may predispose them to have the potential for developing a specific ability?

One account that may be of relevance in this context is provided by Frith and colleagues (Frith, 1989; Shah and Frith, 1993; Frith and Happé, 1994). They have proposed that autistic individuals tend to focus on parts and details rather than on total configurations [see also Mottron and Belleville (1993, 1995)]. Such attention to segments and single elements seems to underlie their high performance on tests such as the block design test (Wechsler, 1981) or the hidden figures test (Witkin et al., 1971). Frith and Happé argue that this 'lack of coherence' is present on the perceptual as well as the semantic level of autistic information processing. Thus, the segmentational cognitive style of individuals with autism, a style which may automatically segment experience into component parts, may have facilitating consequences for their performance on some aspects of information processing (Happé, 1999).

We have tried to link such a cognitive bias and what it entails to explain the predominance of autistic individuals in the savant population (Pring et al., 1995; Heaton et al., 1998). The same cognitive style may also account for the restricted range of savant talent to particular areas, and indeed there is some evidence that segmentational cognitive strategies may also play a significant role in the manifestation of talent in general (Getzels and Csikszentmihalyi, 1976; Pring et al., 1995; Ryder et al., 1999). For savants, the particular cognitive style which focuses on segments or details and local parts may play an important role in gradually developing an association network in memory that models structural and pattern properties of the external world. For 
instance, the calendar is highly organized and rule based, illustrated, for example, by the fact that every 28 years the same date will fall on the same day of the week. The attention and subsequent memory for individual dates may facilitate the early stage of acquisition of what are initially independently represented items. Such uniquely specified representations can then later be linked to others with some facility. In the same way, for example, absolute pitch abilities are found amongst all musical savants (Miller, 1989) and indeed in many children with autism but without musical training (Heaton et al., 1998). Such abilities are based on associating a uniquely specified pitch representation with a verbal label. Thus, the retention of such items may provide the first basic features of a system which, with the acquisition of later items, may 'kick start' the eventual emergence of structured association networks (i.e. musical, calendrical or numerical) underlying the outstanding performances.

How can we monitor the emergence of the talent-related high-level abilities of savants? If we get individuals to practise a particular new skill (Chase and Ericsson, 1981; Ericsson and Faivre, 1988) we are likely to miss out the role of inherent disposition and the early development of this potential [see also Wilding and Valentine (1994)]. On the other hand, in all studies of the specific high-level abilities of savants, the acquisition process has been completed before the case studies have begun. As far as we are aware, there is only one controlled investigation (Smith et al., 1993; Smith and Tsimpli, 1995) which attempted to look at savant performance on a new, but talent-related task. They were concerned with the unusual case of a savant multi-linguist, Christopher, first studied by O'Connor and Hermelin (1991). Subsequently, Smith and Tsimpli taught Christopher Berber, a language previously unknown to him, as well as a newly constructed artificial language. In both these instances, the savant acquired the two new vocabularies, as well as the morphology, with amazing speed and significantly faster than normal controls (i.e. with less practise). In the same way we could perhaps try to teach a calendrical calculator the calendar of Mars, for example. Instead we adopted a somewhat simpler, but essentially similar, approach. We happened to find that Peter, an individual with savant calendar calculating ability, knew that the letters $\mathrm{B}, \mathrm{C}$ and $\mathrm{Q}$, for example, were the second, third and 17th letters of the alphabet, respectively, and could supply this information very quickly indeed. This letter/number association ability appears to have been spontaneously formed and offered a chance to ask whether this simple ability could be extended to hitherto unpractised letter/number associations and manipulations. The aim of the current study was to explore this in more detail, and crucially to include new letter/number correspondences. These, we were assured, had never been considered before by this individual. In this way, we tried to explore the extent and flexibility to which an established knowledge base can serve for the instant mastering of hitherto unpractised operations.

\section{Participants}

Peter is a 46-year-old man with a diagnosis of autism and exceptional calendrical calculating ability. Peter's range in calendar calculating ability covers a span of some 250 years in the past to about 50 years into the future. His average speed for supplying the day of the week on which a fairly recent date falls (e.g. 1939-2002) is about 4 s, but this increases to about $26 \mathrm{~s}$ for the more remote dates (e.g. 2050, 1903, 1896, etc.). He never makes mistakes within span. His arithmetic ability is quite good. He can perform addition, subtraction, multiplication and division, and can calculate square roots of two-figure numbers. It is relevant that he is also able to add in $26 \mathrm{~s}$ and $28 \mathrm{~s}$, the former being relevant to the alphabet and the latter to calendar structure (the calendar repeats itself every 28 years). However, he cannot understand arithmetical problems presented in an everyday, practical, verbal context, such as the problems found in adult intelligence tests.

$\mathrm{He}$ is relatively high functioning with a Ravens progressive matrices (Ravens, 1969) IQ of 108 and a Peabody vocabulary level IQ of 78. When tested on the Wechsler Adult Intelligence Scale-Revised (WAIS-R; Wechsler, 1981) he obtained a subtest pattern typical of those with autism, with vocabulary and comprehension subtest scores of 4 and 3, respectively, but block design and object assembly scores of, respectively, 10 and 9 . He also possesses absolute pitch, although he has no special musical ability and therefore is not a musical savant.

There were two other participants involved in the present study, a professor of mathematics and a control individual who agreed to participate in the study. The mathematician reported not having any special practise at letter/number associations, except inasmuch as being interested in puzzles and mathematical games that very occasionally involve letter/number pairings. The control, a university department secretary, reported being reasonably good at mathematics and not particularly intimidated by numbers. No intelligence test results from the two control participants were available and this omission will be dealt with further on.

\section{Experiment 1}

\section{Design and procedure}

Experiment 1 consisted of testing letter/number associations across the entire alphabet with the exception of the first and last letter/number pairs (i.e. A/1 and Z/26) which were not included.

Each testing session began by showing the participants a display that contained all the letter/number sequences (see Fig. 1). The participants looked at this for up to $1 \mathrm{~min}$ before it was removed and they were ready to proceed with the experimental trials. The experimenter would say a number and the participant would respond with the corresponding letter name. The speed (measured with a stopwatch) of the response was noted before proceeding to the next trial, but feedback was not provided to the participant until the end of 
ABCDEFGH I J KL M N OPQRSTUVW $X Y Z$

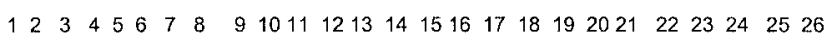

Fig. 1. Experiment 1. Number and letter correspondences for one alphabet First third, letters B-I; second third, letters J-Q; last third, letters R-Y. The actual display was hand-written to avoid spacing problems. Test item 13, correct response $\mathrm{M}$.

Table 1. Mean reaction times (s) and standard deviations across positions in the alphabet (A-Z) obtained by the savant, the mathematician and the control in experiment 1

\begin{tabular}{|c|c|c|c|}
\hline Participant & First third, B-I & Second third, J-Q & Last third, R-Y \\
\hline Savant & $1.7(0.6)$ & $2.3(1.2)$ & $1.6(0.3)$ \\
\hline Mathematician & $1.9(1.0)$ & $2.5(0.9)$ & $2.5(1.0)$ \\
\hline Control & $2.1(0.8)$ & $4.1(0.9)$ & $5.2(2.2)$ \\
\hline
\end{tabular}

the experiment, when accuracy for the letter names given was assessed. The numbers $2-25$ were presented in pseudorandom order, requiring the participant to provide all the corresponding letters of the alphabet except A and Z. None of them had any trouble understanding what was required.

Three conditions were compared, the first, middle and final third of the alphabet (see Fig. 1).

\section{Results}

The mean scores across trials and conditions are provided in Table 1. The response times for self-corrected errors were included in the analyses throughout. In order to analyse these data, we carried out an item analysis such that each trial could be entered separately as examples of savant, expert or control responses. Thus, the first factor was the participant. The second factor was that of the position in the alphabet, with three levels: beginning, middle and end portion of the alphabet. Generalization of the findings to the populations from which the participants were drawn was therefore not possible and as the power of the analysis was low, the results must be treated with caution. The pattern of the data was, however, reasonably consistent and all analyses that were carried out showed the same pattern. Therefore, it was agreed on expert advice that an item analysis, as suggested by Horn and Hofer (1992), was most appropriate in this case.

The savant and the control made no errors at all and the mathematician made two self-corrected errors. The ANOVA showed that there was a significant main effect of participant $(F=23.348, P<0.0001)$ and a significant effect of position of the letter in the alphabet $(F=7.322, P<0.004)$. There was also a significant participant $\times$ position interaction $(F=5.463, P<0.001)$. The control participant took significantly longer than the other two overall (simple effects tests: $F=7.43, P<0.016$ ), but this was particularly marked at the middle and end part of the alphabet (simple effects tests: $F=7.58, P<0.003 ; F=14.70, P<0.001)$. In the first part of the alphabet no significant differences emerged.
The difference in speed between the savant and the mathematician was not significant.

\section{Discussion}

The first point to note is that the mathematician's fast, accurate performance was matched by that of the savant and both were faster than the control, at least for trials measuring the middle and end of the alphabet. Such a result seems to indicate that the associations of letters and numbers had been established by both the mathematician and the savant. In the case of the control, however, only the first few pairings were quickly provided. The results suggest that the control calculated the correct letter by counting in a serial direction starting at the beginning of the alphabet, thus accounting for a pronounced slowing down as the letter distance increased away from A. However, there was no such effect of position noted with respect to both the savant's and the mathematician's performance. This suggests that they probably had equal access to the paired representations across the whole alphabet and implicates the use of a direct retrieval strategy, probably by using already established 'benchmarks'. Thus, these two participants would not have had to go through the whole series of letters and numbers starting at $A / 1, B / 2$ until they reached the target letter/number pairing. Instead they could have pre-established memory representations for at least some of the pairings and used these as anchor points from which to calculate the target. In fact, the mathematician offered this explanation spontaneously. He even felt that it was unusual for everyone not to have noted and remembered that the middle positions of the letter/number associations were $\mathrm{M} / 13, \mathrm{~N} / 14, \mathrm{~L} / 12$. The use of benchmarks noted in the performance of calendrical calculations (Hermelin and O'Connor, 1986; Heavey, 1997) appears to play an important part in the acquisition and execution of calendar calculation. In the present context, the use of such benchmarks would of course confound any increase in time with increased distance from the beginning of the alphabet, and their absence can be seen in the performance of the control.

The number of benchmarks for any one person is likely to vary. In the case of the mathematician, he suggested having about 12 , the savant could not give any verbal account, and the control participant had about five established letter/ number associations, but only at the beginning and end of the alphabet (i.e. A/1, B/2, C/3, Y/25, Z/26). Such individual, paired representations could be seen as sharing some similarities with the memory structure of musical savants and others who have absolute pitch (Miller, 1989; Heaton et al., 1998). There, the individual pitch and verbal label are stored together but independently from other pairs (i.e. not as part of a sequential or relational musical memory trace). Such unique representations, underling absolute pitch ability, can then be accessed directly without reference to other notes or verbal labels. Individuals differ in the number of pitch/label associations they seem to retain, so that while some individuals can label two octaves, others retain just four notes (Miller, 1989). 


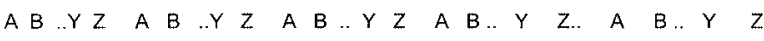

$\begin{array}{lllllllllllll}12 & 2526 & 27 & 28 & 5152 & 5354 & 7980 & 81 & 82 & 103 & 104 & 105106 & 129130\end{array}$

Fig. 2. Five alphabet arrangement for experiment 2. First third, letters B-I; second third, letters J-Q; last third, letters R-Y. The actual display was handwritten to avoid spacing problems. Test item 13, correct response $\mathrm{M}$.

\section{Experiment 2}

In experiment 1, the letter/number pairings tested occur quite commonly in everyday circumstances. However, in the following studies we were interested in testing the calculation abilities of the individuals for new unpractised and unfamiliar associations. Thus, we asked them to provide accurate letter/ number pairings of items that they were very unlikely to have come across before. The question asked here is not so different from the one referred to in experiment 1. Namely, is there any evidence of direct access to individual pairings and were the unfamiliar computations involved adopted by all three individual participants?

What we were asking is whether the savant's performance was based primarily on practise with one alphabet and established representations, or whether in a new situation an algorithm could be (a) mentally formulated and (b) applied. Such questions come close to the investigations of calendar calculators where researchers have been interested in how limited calendar information can be extended to cover many hundreds of years. In that context we have argued elsewhere that it may be that 'birthday' information may allow the extraction of a rich calendar knowledge database via a connectionist-type network and that memorizing individual dates may play an important role in the aetiology of the talent (Heavey et al., 1999).

In the following study we showed the participants five alphabet/number series in a sequential order (see Fig. 2).

\section{Design and procedure}

As in experiment 1 the participants were first shown a display (see Fig. 2) wherein five alphabets were shown alongside their associated numbers. Again this display was shown for up to $1 \mathrm{~min}$, after which it was taken away and the experimental trials proceeded. In each trial a series of randomly selected numbers was given by the experimenter and the task of the participant was to supply the corresponding letter of the alphabet. The participants had no trouble understanding what was required of them and it was made clear that not all of the letter/number associations would be tested. In fact, there were 27 trials in all, eight falling within each alphabet sequence and presented to the participants in a pseudo-random order. Thus, a participant was asked, for instance, 'what goes with 67?', 'what goes with 13?'.

The same design as described in experiment 1 was used, such that there were two factors, participant responses and position in the alphabet, in this case with five levels, referring to each alphabet involved in the study.

\section{Results}

The control participant kindly tried to participate in this study, but when it came to this experiment she was aware that she was making many mistakes and became overwhelmed by the mental arithmetic demands. As the study continued she was prone to interference from previous trials and this undermined her confidence. The control made least errors in the first three alphabet positions and we have therefore decided to include her mean response times in Table 2, although her data were not analysed.

The ANOVA showed that the speed of calculation was significantly quicker for the mathematician when compared with the savant $(F=2.787, P<0.039)$ and there was a significant alphabet position effect, with an overall trend for an increase in speed with increasing distance from the first alphabet $(F=14.399, P<0.0001)$.

\section{Discussion}

Here, all the participants could deal speedily with the first alphabet (as they had in experiment 1). However, while the mathematician and the savant showed no effect of the extra demands of this task compared with the previous one, for the first alphabet position, the control took longer. Her response times for even the first alphabet were slower in the context of this more demanding task. It seems as though her attentional resources, when focused on the whole task demands, were limiting her speeds of mental calculation involved, even in the easiest trials. No such performance limitations for the first alphabet positions were noted for the savant and the mathematician and this may provide some evidence of their 'automatic' access to first alphabet positions afforded by their expertise.

The performance of the mathematician was significantly faster than that of the savant throughout, although the pattern of responding was very similar for both, with decreasing speeds according to alphabet position. At least for the savant, the last two alphabets seemed to reflect the extra processing time that may be expected from dealing with the larger numbers involved. To carry out this task successfully, the participant first needs to determine into which alphabet range the number is likely to fall and then subtract the appropriate number. For instance, they may go through the 26 times table until the target number is smaller than the computed number and then subtract either $0,26,52,78,104$ depending on which alphabet of the five potential alphabets is involved in that trial or alternatively by remembering which number goes with $\mathrm{A}$ in each alphabet and subtract this from the target. This has the effect of computing a target number falling between 1 and 26 from which point the corresponding letter can be calculated.

Interestingly, the performance of the mathematician for the final alphabet positions was much quicker than would have been expected on the basis of the overall pattern shown. It seems not unlikely that he adopted a special strategy for 


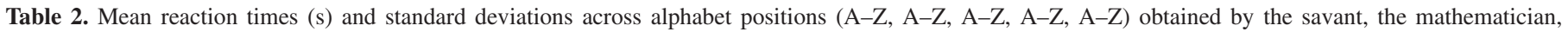
and the control ${ }^{\mathrm{a}}$ in experiment 2

\begin{tabular}{|c|c|c|c|c|c|}
\hline Participant & First alphabet & Second alphabet & Third alphabet & Fourth alphabet & Fifth alphabet \\
\hline Savant & $2.3(1.0)$ & $5.0(1.9)$ & $6.0(2.1)$ & $8.9(2.5)$ & $8.4(2.9)$ \\
\hline Mathematician & $2.5(1.2)$ & $3.9(1.7)$ & $5.4(2.7)$ & $7.7(4.2)$ & $4.3(1.7)$ \\
\hline Control & $5.4(1.4)$ & $11.5(9.7)$ & $17.8(7.7)$ & Not available & Not available \\
\hline
\end{tabular}

aErrors in her calculations meant that the control's data could not be analysed.

the last alphabet in the series and thus for trials in which the numbers went from 106 to 129 . He could then speedily subtract 104 and bring down his mean speed when compared with the other alphabet positions. This appreciation of numerical structure leads to a bypassing of some of the steps needed in the calculation process and could be why he was particularly fast in the final alphabetic position. However, it should be remembered that there was no significant interaction between position and participant in this study and thus the increase in speed found in the last alphabet for the mathematician may not be significant.

The savant performance illustrated here makes an explanation of his ability in terms of practise alone hard to sustain. Instead, he could rapidly form new associations between numbers and letters affording an ease in calculation only matched and just surpassed by that of a mathematician.

\section{Experiment 3}

In experiment 3 we reversed the familiar direction in which alphabetic letters normally occur, such that $\mathrm{Z}$ was at the beginning and $\mathrm{A}$ was at the end. We asked the participants if they could form new associations between $\mathrm{Z}$ and $1, \mathrm{Y}$ and 2, $\mathrm{X}$ and 3, and so on until $\mathrm{C}$ and 24, B and 25 and $\mathrm{A}$ and 26.

In experiment 1 , we suggested that the savant's performance was probably based on the generation and application of a rule that defined the structure of the data set and earlier we linked this with the underlying procedure for dealing with the calendar. Thus, in experiment 1 it was established that the savant had recognized the correspondence of two ascending series, that is $\mathrm{A}-\mathrm{Z}$ and $1-26$. In experiment 2 we asked whether he could generate and apply a rule that made use of his alphabet knowledge in conjunction with arithmetical knowledge, that is subtract the target number from 26. The next question was whether the savant could generate and use a rule for which there was no predetermined correspondence between the items to be associated. Some flexibility would be required for this, as the first letter of the alphabet would now have to be linked with the last number of the series.

Thus, we presented a reversed alphabet and asked the participants to supply the appropriate letter.

\section{Design and procedure}

In this experiment we asked all three participants to provide the correct letter of the alphabet $(\mathrm{Z}-\mathrm{A})$ that corresponded to
Table 3. Mean reaction times (s) and standard deviations across alphabet positions in the reversed alphabet $(\mathrm{Z}-\mathrm{A})$ obtained by the savant, the mathematician and the control ${ }^{\mathrm{a}}$ in experiment 3

\begin{tabular}{llll}
\hline Participant & First third & Second third & Last third \\
\hline Savant & $6.0(2.5)$ & $5.4(2.8)$ & $6.0(4.0)$ \\
Mathematician & $3.7(1.0)$ & $4.0(1.0)$ & $3.0(0.8)$ \\
Control & $7.1(6.2)$ & $7.7(10.1)$ & $4.1(9.6)$ \\
\hline
\end{tabular}

aErrors in her calculations meant that the control's data could not be analysed.

the number (1-26) (i.e. with the letters in reverse order). As before they were given $1 \mathrm{~min}$ to view the correspondence between the letters and numbers that was now being made. After this time the display was taken away and the trials began. There were 24 trials, pseudo-randomly presented and including all pairs except A/26 and Z/1. Performance across the beginning (condition 1), middle (condition 2) and end (condition 3) part of the alphabet was compared.

\section{Results}

The control data are provided for comparison purposes, but unfortunately a number of errors were made in each condition (condition 1: two errors; condition 2: four errors; condition 3: two errors), thus making it impossible to include the control's data in the statistical analysis (Table 3 ).

Neither the savant nor the mathematician made any errors. The ANOVA of respective times showed that while there was no effect of speed resulting from the position in the alphabet of the target $(F=0.572, \mathrm{~ns})$, there was a significant speed advantage overall for the mathematician in comparison with the savant $(F=29.336, P<0.0001)$. There was no significant interaction $(F=0.861, \mathrm{~ns})$.

\section{Discussion}

In this experiment, where a backward letter series had to be linked with a forward series of numbers, the mathematician was significantly faster than the savant. However, the savant could manage the task efficiently and without errors. The overall pattern of results for the mathematician and the savant were very similar. The first point to note is that here, as in experiment 1 , there were no serial position effects. ${ }^{1}$ This result seems to support the interpretation that once the participants had applied the appropriate rule, namely to subtract the number provided from 27 , to 'un'-reverse the 


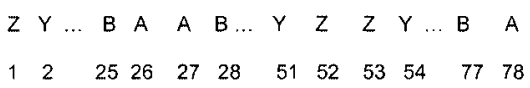

Fig. 3. Three alphabet arrangement for experiment 4 . The actual display was hand-written to avoid spacing problems.

Table 4. Mean reaction times ( $s$ ) and standard deviations across alphabet positions ( $\mathrm{Z}-\mathrm{A}, \mathrm{A}-\mathrm{Z}, \mathrm{Z}-\mathrm{A})$ obtained by the savant and the mathematician in experiment 4

\begin{tabular}{llll}
\hline Participant & $\begin{array}{l}\text { First alphabet, } \\
\text { Z-A }\end{array}$ & $\begin{array}{l}\text { Second alphabet, } \\
\text { A-Z }\end{array}$ & $\begin{array}{l}\text { Third alphabet, } \\
\text { Z-A }\end{array}$ \\
\hline Savant & $\begin{array}{c}10.6(6.9) \\
\text { Mathematician }\end{array}$ & $\begin{array}{l}9.4(3.7) \\
4.9(1.9)\end{array}$ & $\begin{array}{c}10.8(5.0) \\
6.1(2.0)\end{array}$ \\
\hline
\end{tabular}

alphabet, this process would then allow direct access to letter/ number correspondences learnt before the study began. This extra step could account for the slower time of the savant, as seen in Table 3 compared with Table 1.

\section{Experiment 4}

In the final experiment we aimed to set the participants a problem that would require a flexible approach along with substantial memory demands, both in terms of task analysis as well as execution. Thus, while the number series involved was $1-72$, this time the first and last alphabet positions were reversed, while the middle one was not (see Fig. 3 for clarification). The control participant was not asked to take part in this experiment.

\section{Design and procedure}

The design and procedure were the same as in previous experiments, with nine trials per alphabet, and the numbers presented in a pseudo-random order.

\section{Results}

The results of experiment 4 are given in Table 4 .

Neither participant made any errors in this complex mental task. The ANOVA revealed only one significant effect. The responses of the mathematician were significantly faster than those of the savant $(F=27.129, P<0.0001)$.

\section{Discussion}

It is remarkable how well both participants succeeded in this task, particularly as their performance was error free. They could memorize the order of the transformations as well as producing the appropriate calculations with some facility. Both participants found it relatively easy to remember that the first and last alphabet positions related to 'reversed order' manipulations and that the middle alphabet was in the 'usual order'. Thus, the fact that they made no errors does not only indicate that the calculations required were relatively straightforward, but that simply retaining the structural properties of the three alphabetic series did not cause problems. One way to complete the task successfully would involve the participants repeating the procedure outlined in the discussion of experiment 3 , namely to subtract target numbers falling in the range 1-26 from 27 and to subtract target numbers falling in the range 53-72 from 73. Target numbers falling in the range $27-52$ could be dealt with by subtracting 26 from them. All of these suggested computations are predicated on the assumption that the aim of the participant is to adjust target numbers so that they fall within the familiar $\mathrm{A} / 1$ to $\mathrm{Z} / 26$ range. There are of course other alternative solutions based on visualization and other miscellaneous strategies.

The important overall conclusion was that while the mathematician could bring to bear substantial speed advantages, both the savant with an IQ of 90 and the professor of mathematics, applied logical, flexible and mathematical rules to solve the task, with its increased memory load, compared with the previous studies, both rapidly and accurately.

\section{Summary and conclusions}

In spite of the inherent drawbacks with this investigation, both with regard to the data analysis and the single case study approach, the experiments presented here have nevertheless provided a coherent picture. The first startling finding is that in all four experiments, where three of the tasks were unpractised, the savant made no errors at all. The mathematician made very few errors, but all were self-corrected. In contrast, although the control made no errors in linking two well-established consecutive series of items, when the series were extended, or the nature of the relationship between the items was changed, she could no longer cope. The errorfree performance of the savant is indicative of a fast, spontaneous recognition of new rules and relationships. Thus, if we are justified in the conclusion that Peter had not practised tasks 2, 3 and 4 then we have demonstrated that whatever representations have been developed by Peter are flexible enough to be recalibrated for the fast extraction of related information.

The facility and accuracy with which the savant could deal with the letter/number correspondences involved here seem to suggest, at least to us, a remarkable ability to represent such stimuli in memory accurately. Such accuracy may well aid early acquisition of a knowledge base and play a role in all savant talents. Why should they be so accurate? Perhaps it is related to the weak coherence, at least in the perceptual domain, which protects the single internal representations from integration and interference. For example, Mottron and Bellevile $(1993,1995)$ argue that autistic artists have anomalies in hierarchical organization and this deficit, which gives rise to an equivalent processing status for local as well 
as global elements, can explain the accuracy of perspectiverelated memory representations in some savant drawings. The early acquired pieces of knowledge retain their veracity and thus form an excellent basis for evolving complex knowledge structures. Without such veracity it would not be possible to augment a database, as any errors built into a system early would clearly prevent it from functioning adequately.

We have tried to link the specific ability reflected here with an autistic cognitive style that favours retention of uniquely specified representations, and moreover, to be able to use these representations as a basis from which much larger structures evolve and are made operational. From this we conclude that practise may allow speeds to increase and processes to become somewhat automated, but practise alone cannot explain the performance of the savant described here, or indeed the savant phenomenon in general.

It seems unlikely that the different IQ levels of the participants played a crucial role in determining the results obtained. One of the controls can be assumed to have had an intelligence level that would at least have fallen within the average normal range and which would certainly have been higher than Peter's. Yet her performance on the experimental tasks was well below that of the savant. On the other hand, although presumably the mathematician had a much higher than average IQ, his and Peter's facility to deal with the problems was very similar.

In addition, while in experiment 1 the secretary needed more time to deal with the middle part of the presented sequence than with its beginning and end, this was not so for the other two participants. This indicates that similar strategies were used by both these individuals. In another context, results confirming such a conclusion were obtained with normal and savant artists (Pring et al., 1995).

Peter's calendrical skill was far out of reach for the mathematician, yet both these talented individuals adopted new sets of sequential rules with the same ease. It is thus possible that the tendency towards perceiving and retaining single items of information may enable not only savants, but also others with specific talents, to retain, recombine and transform data and re-integrate it in novel contexts.

\section{Acknowledgements}

These studies were based on an observation and data collected by Peter Lee and Alison Manners and we are indebted to them. We are also very grateful to all the participants for their help in this study.

\section{Note}

Although we need to bear in mind the design limitations of the study in terms of the number of trials etc. and the resultant high probability of a type 2 error.

\section{References}

Binet A. Psychologie des Grandes Calculateurs (et de Doueurs d'Echecs). Paris: Hachette, 1894.

Birch LL. Baseline differences, attention, and age differences, in time-sharing performance. Journal of Experimental Child Psychology 1978; 25: 505-13.

Case R. Neo-Piagetian theories of child development. In: Sternberg RJ, Berg CA, editors. Intellectual development. Cambridge: Cambridge University Press, 1992.

Chase WG, Ericsson KA. Skilled memory. In: Anderson JR, editor. Cognitive skills and their acquisition. Hillsdale: Erlbaum, 1981

Csikszentmihalyi M. Fruitless polarities. Behavioural and Brain Sciences 1998; 21: 411.

Ericsson KA, Chase WG. Exceptional memory. American Scientist 1982; 70: 607-15.

Ericsson KA, Faivre IA. What's exceptional about exceptional ability? In: Obler LK, Fein D, editors. The exceptional brain. New York: Guildford Press, 1988.

Ericsson KA, Tesch-Romer C, Krampe RTh. The role of practice and motivation in the acquisition of expert-level performance in real life. In: Howe MJA, editor. Encouraging the development of exceptional abilities and talents. British Psychological Society, 1990.

Ericsson KA, Krampe C, Tesch-Romer RTh. The role of deliberate practice in the acquisition of expert performance. Psychological Review 1993; 100 : $363-406$

Frith U. Autism: explaining the enigma. Oxford: Blackwell Scientific, 1989.

Frith U, Happé FGE. Autism: beyond 'theory of mind'. Cognition 1994; 50: 115-32.

Getzels JW, Csikszentmihalyi M. The creative vision: a longitudinal study of problem finding in art. New York: John Wiley, 1976.

Happé FGE. Autism: cognitive deficit or cognitive style? Trends in Cognitive Sciences 1999; 3: 216-22.

Heaton P, Hermelin B, Pring L. Autism and pitch processing: a precursor for savant musical ability? Music Perception 1998; 15: 91-305.

Heavey L. Memory in calendar calculators. Unpublished $\mathrm{PhD}$ thesis. University of London, 1997.

Heavey L, Pring L, Hermelin B. A date to remember: The nature of memory in savant calendrical calculators. Psychological Medicine 1999; 29: 145-60.

Hermelin B, O'Connor N. Idiot savant calendrical calculators: Rules and regularities. Psychological Medicine 1986; 16: 885-93.

Hermelin B, O'Connor N, Lee S. Musical inventiveness of five musical idiotsavants. Psychological Medicine 1987; 17: 685-94.

Horn JL, Hofer SM. Major abilities and development in the adult period. In: Sternberg RJ, Berg CA, editors. Intellectual development. Cambridge: Cambridge University Press, 1992.

Howe MJA, Davidson JW, Sloboda JA. Innate talents: Reality or myth? Behavioral and Brain Sciences 1998; 21: 399-442.

Karmiloff-Smith A. Constraints on representational change-Evidence from children's drawings. Cognition 1990; 34: 57-83.

Miller L. Musical savants: Exceptional skills in the mentally retarded. Hillsdale: Erlbaum, 1989.

Miller L. Sensitivity to sequential structure in musical savants. American Journal on Mental Retardation 1995; 99: 391-8.

Mottron L, Belleville S. Study of perceptual analysis in a high level autistic subject with exceptional graphic abilities. Brain and Cognition 1993; 23: 279-309.

Mottron L, Belleville S. Perspective production in a savant autistic draughtsman. Psychological Medicine 1995; 25: 639-48.

O'Connor N, Hermelin B. Idiot savant calendrical calculators: Maths or memory? Psychological Medicine 1984; 14: 801-6.

O'Connor N, Hermelin B. The memory structure of idiot-savant mnemonists. British Journal of Psychology 1989; 80: 97-111.

O'Connor N, Hermelin B. A specific language ability. American Journal of Mental Ability 1991; 95: 673-80.

Pring L, Hermelin B. Bottle, tulip and wineglass: semantic and structural picture processing by savant artists. Journal of Child Psychology and Psychiatry 1993; 34: 1365-85.

Pring L, Hermelin B, Heavey L. Savants, segments, art and autism. Journal of Child Psychology and Psychiatry 1995; 36: 1065-76.

Ravens JC. Standard progressive matrices. London: Lewis, 1969

Rimland B. Savant capabilities of autistic children and their cognitive implications. In: Serban G, editor. Cognitive defects in the development of mental illness. New York: Brunner/Mazel, 1978. 
Ryder N, Pring L, Hermelin B. The puzzle of the artistic savant: Generativity in autism. British Psychological Society Meeting, London, 1999.

Selfe L. Nadia: A case of extraordinary drawing ability in an autistic child. London: Academic Press, 1978.

Shah A, Frith U. Why do autistic individuals show superior performance on the block design task? Journal of Child Psychology and Psychiatry 1993; 34: $1351-64$

Sloboda JA, Hermelin B, O'Connor N. An exceptional musical memory Music Perception 1985; 3: 155-70.

Sloboda JA, Davidson JW, Howe MJ. Is everyone musical? The Psychologist 1994; 7: 349-54.

Smith N, Tsimpli I. The mind of a savant. Oxford: Blackwell, 1995.

Smith N, Tsimpli IM, Ouhalla J. Learning the impossible - the acquisition of possible and impossible language by a polyglot savant. Lingua 1993; 91: 279-347.

Takeuchi AH, Hulse SH. Absolute pitch. Psychological Bulletin 1993; 113 : 345-61.

Wechsler D. Wechsler Intelligence Scale for Children-Revised. New York: The Psychological Corporation, 1981.

Wilding J, Valentine E. Memory champions. British Journal of Psychology 1994; 85: 231-44.

Witkin HA, Oltman PK, Raskin E, Harp S. A manual for the embedded figures test. California: Consulting Psychologist Press, 1971.

Received on 11 October, 2000; resubmitted on????; accepted on 29 January, 2002

\section{Numbers and letters: exploring an autistic savant's unpractised ability}

\section{Pring and B. Hermelin}

\section{Abstract}

This paper describes an individual with autism and high-level calendar calculation ability who could perform a set of unpractised letter/number association tasks. The savant's performance was compared with that of two control participants, one a departmental secretary and the other a professor of mathematics. The facility with which the savant could master the rules governing the relationships between the series of items suggests that he possessed a flexibility of mental processing transcending his ability of calendar calculation. Furthermore, he could recalibrate previous knowledge to solve new hitherto unpractised tasks. When presented with novel problems, the savant, unlike the mathematician, made no initial errors at all on any of the presented tasks, thereby indicating his fast and spontaneous recognition of new rules and of new relationships between items. It is concluded that a cognitive style of 'weak central coherence' as adopted by autistic savants may protect single representations from being retained in the form of stable enduring wholes, and that such a segmentation strategy may allow for the transformation, reorganization and reconstruction of the relationship between single items of information.

\section{Journal}

Neurocase 2002; 8: 000-000

\section{Neurocase Reference Number:} O???

\section{Primary diagnosis of interest}

Intelligence, talent and autism

\section{Author's designation of case} Peter

\section{Key theoretical issue}

- Role of practise in special abilities shown in savants

Key words: savant; autism; talent; practise

\section{Standardized assessment}

Ravens progressive matrices, Peabody vocabulary, Wechsler Adult Intelligence Scale-Revised (WAIS-R)

\section{Language}

English 